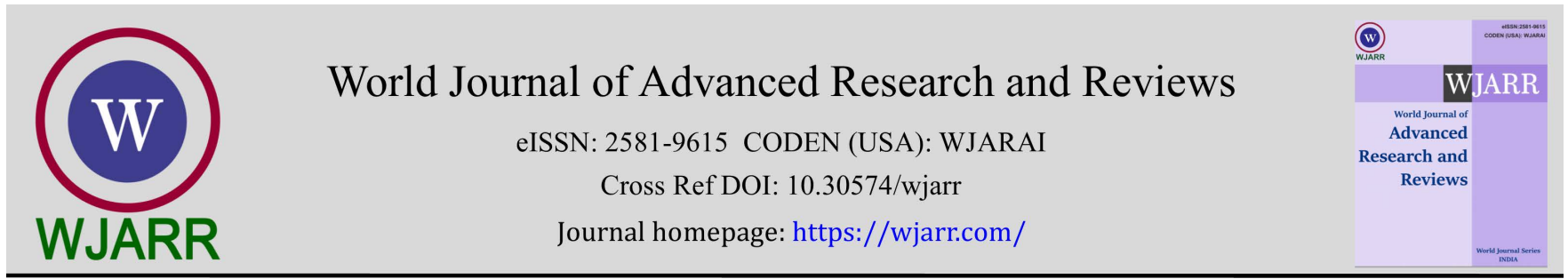

(RESEARCH ARTICLE)

\title{
Isolation of Bacillus thuringiensis strains from Saudi Arabia soil and study of their potential efficiency against the lepidopteran pest Ephestia kuehniella
}

\author{
Fidaa Ibrahim Kallaf 1,¥, Hanen Boukedi 2, , Dalel Daâssi ${ }^{1}$ and Lobna Abdelkefi-Mesrati 1, 2, 3, * \\ ${ }^{1}$ Department of Biology, Faculty of Science and Arts at Khulis, University of Jeddah, Jeddah, Saudi Arabia. \\ ${ }^{2}$ Laboratory of Biopesticides, Centre of Biotechnology of Sfax, Sfax, Tunisia. \\ ${ }^{3}$ Higher Institute of Biotechnology of Sfax, University of Sfax, Sfax, Tunisia. \\ $¥$ These authors contributed equally to this work
}

World Journal of Advanced Research and Reviews, 2021, 12(02), 238-245

Publication history: Received on 28 September 2021; revised on 01 November 2021; accepted on 03 November 2021

Article DOI: https://doi.org/10.30574/wjarr.2021.12.2.0568

\begin{abstract}
Insect pests represent a major threat to food crops and human health, and therefore have to be combated in several ways, including chemical methods. However, researchers demonstrated that these molecules are dangerous for the farmers, consumers and the environment in general. For this reason, scientists permanently searched environment friendly alternatives such as the use of the bacterium Bacillus thuringiensis classified as one of the best insect pathogens. This microorganism is known by its ability to produce two types of insecticidal proteins, Vegetative insecticidal proteins (Vip) and delta-endotoxins produced during vegetative and sporulation stages of growth, respectively.

In the present study, 15 B. thuringiensis strains were isolated from soil collected from different regions in Saudi Arabia (Al Baha, Jeddah, Khulis and Yanbu). B. thuringiensis isolates were then classified according to the shape of their parasporal crystals identified under microscope and proteins content of these crystals. Delta-endotoxins efficiency of the different isolates was investigated and promising strains were identified as very active. After 5 days-treatment, $B$. thuringiensis isolates 14 and 7 killed Ephestia kuehniella larvae with low LC50 of about 59.18 and $65.67 \mu \mathrm{g} / \mathrm{cm}^{2}$, respectively.
\end{abstract}

The results described in the present study proved that the new $B$. thuringiensis isolates could be of a great interest in the control of lepidopteran pests by using their delta-endotoxins in bioinsecticide formulations.

Keywords: Bacillus thuringiensis; Delta-endotoxins; Biocontrol; Ephestia kuehniella

\section{Introduction}

Over the past decades, protecting the environment has increasingly become a major global concern. In agriculture, it is undeniable that agricultural expansion and productivity must be achieved through optimal management of pests and weeds $[1,2]$. Thus, to protect crops and to increase the productivity of the agricultural and forestry sectors, chemical insecticides have been used extensively [3]. However, growing public concerns about the potentially harmful effects of these chemical molecules on the environment and humans have led the scientific community to seek alternatives to chemical control $[4,5]$. One of the ways of protecting consumers and their environment is the partial or total substitution of chemical pesticides by biopesticides. In this context, the world market for biopesticides continues to increase in parallel with a decline in sales of chemical pesticides, and substances based on Bacillus thuringiensis (B.

\footnotetext{
${ }^{*}$ Corresponding author: Lobna Abdelkefi-Mesrati

${ }^{1}$ Department of Biology, Faculty of Science and Arts at Khulis, University of Jeddah, Jeddah, Saudi Arabia.

Copyright (@ 2021 Author(s) retain the copyright of this article. This article is published under the terms of the Creative Commons Attribution Liscense 4.0.
} 
thuringiensis) occupied the first place since decades. In fact, since 2006, this entomopathogenic bacterium represents $70 \%$ of the world market for microbial biopesticides [6].

In various countries, large quantities of bioinsecticides based on $B$. thuringiensis are used each year in the agricultural sector to fight against crop insects such as the polyphagous pest Spodoptera littoralis and the stored products pest Ephestia kuehniella (E. kuehniella).

Due to its interest in pest's management control programs, B. thuringiensis has been the subject of numerous studies around the world. This Gram positive entomopathogenic bacterium produces various toxins and metabolites that can have different industrial applications, such as delta-endotoxins and Vip proteins.

Delta-endotoxins, known as first generation bioinsecticides, are crystalliferous proteins encoded by cry genes and produced during sporulation phase of $B$. thuringiensis [7]. These Cry toxins have been widely used as a substitute for chemical insecticides in the control of insect pests attacking crops and vectors of diseases.

Second generation bioinsecticides, which are toxins secreted by the bacterium, are called Vip "Vegetative Insecticidal Proteins" [8]. These proteins are known by their specific activity against larvae of Coleoptera (Vip1-Vip2) and Lepidoptera (Vip3) and are expressed during the vegetative phase of growth of many strains of B. thuringiensis. The use of Vip toxins supplemented the insecticidal activity of the Cry proteins and allowed to overcome resistance emergence. Indeed, some studies have shown that Vip3 and Cry proteins do not show sequence homology and do not recognize the same receptors in the intestinal epithelial cells of target larvae [9].

Due to the damages that it caused in stored products, E. kuehniella was used in different studies related with $B$. thuringiensis toxins. E. kuehniella is a cosmopolitan specie, known as the flour moth or "Mediterranean flour moth" and belonging to the Lepidoptera order. The larva, generally whitish in color turning slightly pinkish with a dark head, is 15 to $20 \mathrm{~mm}$ long after full development. The adult, which is 20 to $25 \mathrm{~mm}$ in size, has greyish forewings with fused black dots in the tips and whitish hindwings. The larva of E. kuehniella caused damage mainly on flour, but also on cereal grains, semolina, cookies, pasta and even dried fruits [10].

The aim of the present research was to isolate B. thuringiensis strains, to investigate their potential in producing Cry proteins and to test the efficiency of these toxins in controlling pests such as lepidopteran insects.

\section{Material and methods}

\subsection{Bacillus thuringiensis isolation and growth conditions}

Soil samples were collected from different areas in Saudi Arabia, from Jeddah, Khulis, Al Baha and Yanbu, by using sterilized spatula to collect sample from soil from 1.5 to $2 \mathrm{~cm}$ below the surface. Samples were then saved in sterilized plastic bags with proper labeling and stored at $4^{\circ} \mathrm{C}$ until use.

The sixteen soil samples collected were used to isolate spore-forming bacteria by the acetate selection method described by Travers et al. [11]. In fact, one gram of each soil sample was suspended in $10 \mathrm{~mL}$ of LB broth supplemented with $250 \mathrm{mM}$ Sodium Acetate (pH 6.8). After incubation at $30^{\circ} \mathrm{C}$ with shaking at $200 \mathrm{rpm}$ for $4 \mathrm{~h}$, cultures were heated at $80^{\circ} \mathrm{C}$ for $15 \mathrm{~min}$ to kill vegetative cells. From each sample, $100 \mu \mathrm{L}$ were spread on T3 agar plates then incubated for $72 \mathrm{~h}$ at $30^{\circ} \mathrm{C}$. This technique abled the purchase of spores that germinated, multiplied and entered in sporulation phase.

To confirm the presence of spores and crystals related to the presence of $B$. thuringiensis isolates, pure colonies obtained on T3 agar plates were investigated under light microscope. Then, each parasporal crystal forming isolate was stored and considered as B. thuringiensis.

\subsection{Crystal morphology investigation}

To investigate $B$. thuringiensis crystal morphology, each isolate was grown on $\mathrm{T} 3$ agar plates and incubated at $30^{\circ} \mathrm{C}$ for $96 \mathrm{~h}$. Cultures were then analyzed by light microscopy (Nikon E-100 Eclipse) after staining with Coomassie blue solution to know the crystal morphology [12]. In fact, the smear was prepared on glass slide and after being heated, the sample was stained and washed then observed through light microscope to identify the shape of the crystals. 


\subsection{B. thuringiensis crystal purification, protein quantification and electrophoresis}

After total sporulation on T3 medium, spore-crystal mixture of each B. thuringiensis isolate was suspended in the crystal purification solution ( $2 \mathrm{~mL} \mathrm{NaCl}, 1 \mathrm{M}$; Triton X-100, $0.1 \%$ ). The pellet was harvested by $20,000 \times$ g centrifugation for 10 min then suspended in cold distilled water $(2 \mathrm{~mL})$. After 6 times washing of the pellet in these conditions, it was suspended in $1 \mathrm{~mL} \mathrm{NaOH} 50 \mathrm{mM}$, incubated for $3 \mathrm{~h}$ at $37^{\circ} \mathrm{C}$ then a centrifugation was applied at $20,000 \times \mathrm{g}$ for $5 \mathrm{~min}$ as described by El Khoury et al. [13].

The concentrations of $B$. thuringiensis solubilized crystal proteins were measured with the Bradford assay (Bio-Rad), using bovine serum albumin as a standard then analyzed by sodium dodecyl sulfate poly-acrylamide gel electrophoresis (10\% SDS-PAGE) and visualized by Coomassie blue staining [14].

\subsection{Bioassays against E. kuehniella larvae}

Bioassays were done using the lepidopteran insect $E$. kuehniella known as a stored products pest. For that, a free ingestion technique was used to evaluate the toxicity to E. kuehniella larvae of $B$. thuringiensis delta-endotoxins according to the technique described by different studies [15-18]. Using semolina as diet and different toxin concentrations, each test was replicated three times in the presence of a negative control set. Experiments were done under same conditions of temperature $\left(23^{\circ} \mathrm{C}\right)$, relative humidity $(65 \%)$ and photoperiod (18 h light/6 h dark). Mortality was recorded after treatment ( 3 and 5 days) as lethal concentrations ( $\mathrm{LC}_{50}$ ) calculated by probit analysis [19].

\section{Results and discussion}

\subsection{Soil samples collection and $B$. thuringiensis isolation}

Sixteen soil samples were collected from different regions in Saudi Arabia, from Al Baha, Jeddah, Khulis and Yanbu. Using the acetate selection method, spore-forming isolates were obtained from all the soil samples and the higher frequency of spore-forming isolates was obtained using the soil collected from Khulis. After bacteria isolation from soil samples, about 100 white rough pure colonies were investigated by light microscopy to search the presence of parasporal crystals that confirmed the ability of the isolated strains to produce delta-endotoxins characterizing $B$. thuringiensis from all the other sporulating bacteria. And surprisingly, this type of isolates was found only in the case of the soil collected from Khulis. In the contrast of the other soil samples, those of Khulis were collected from farms in which different plants were cultured and the probability to have insect pests is high making possible the presence and the multiplication of B. turingiensis bacterium. Similar observations were reported by Martin and Travers (1989) [20] and in the total 15 isolates were identified as B. thuringiensis and were investigated in the present work.

\subsection{Classification of $B$. thuringiensis isolates based on crystal morphology}

When B. thuringiensis sporulated cultures were observed by light microscopy, the presence of free spores and crystals, released after complete lysis of the bacterium, was detected (Figure 1).

Table 1 B. thuringiensis crystal shapes under light microscopy

\begin{tabular}{|c|c|}
\hline Isolate number & Description \\
\hline 1,24 & Bipyramidal, cuboidal, spherical \\
\hline $2,4,8$ & Bipyramidal, cuboidal \\
\hline $7,14,16$ & Bipyramidal (different sizes), cuboidal \\
\hline 9 & Bipyramidal \\
\hline $15,22,23,25$ & Bipyramidal, cuboidal, amorph \\
\hline 17,18 & Bipyramidal (different sizes), amorph \\
\hline
\end{tabular}

To study the crystal morphology of the newly isolated B. thuringiensis bacteria, sporulated cells were treated with Coomassie blue. Using this stain, crystal proteins were stained in dark-blue while the spores remain unstained as demonstrated in figure 1. Different crystal shapes were observed for the studied isolates including bipyramidal, amorph, 
cuboidal and spherical. In some cases, the presence of different crystal shapes and sizes was detected for the same isolate (Figure 1; Table 1).

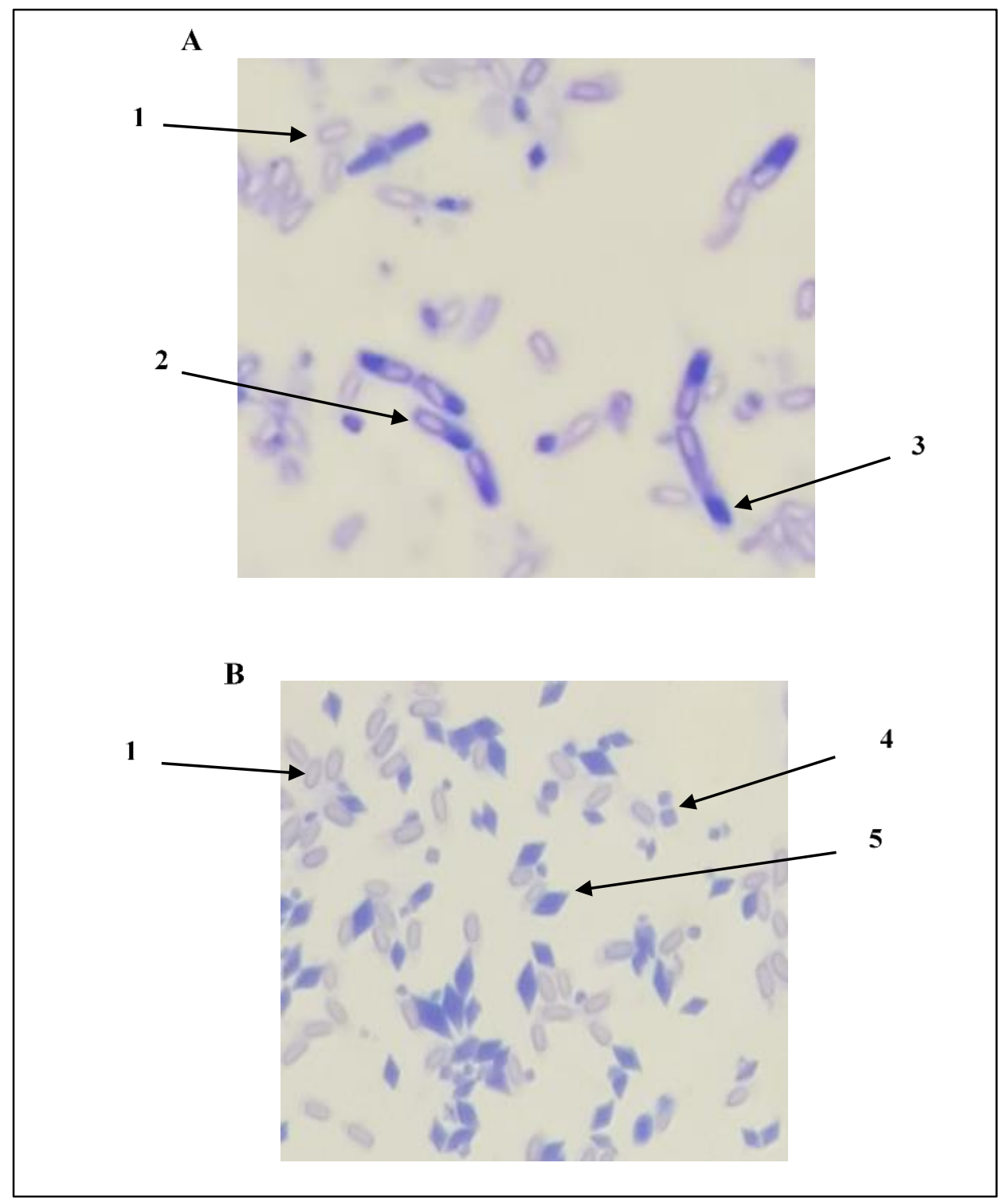

Figure 1 Light microscopy of $B$. thuringiensis isolate 7

(A) Sporulated B. thuringiensis cells before complete lysis; (B) Complete lysis of sporulated B. thuringiensis cells. 1, Free unstained spore; 2, Unstained spore (in the cell); 3, Bipyramidal crystal (in the cell); 4, Cuboidal crystal; 5, Bipyramidal crystal. Magnification: 100x

In Table 1, were summarized the different crystal shapes for the studied B. thuringiensis isolates. All the isolates contained bipyramidal crystals and were classified according to their crystal shapes into 6 classes (Table 1). Nair et al. [21] classified their $B$. thuringiensis collection using the same strategy based on the study of the morphology of the parasporal crystals.

The variation of the crystal shapes from one isolate to another indicated the presence of different $B$. thuringiensis strains in our new isolated collection and promised a variation in the activity spectra between these strains against lepidopteran pests.

\section{3. $\delta$-endotoxins profiling of $B$. thuringiensis isolates}

To have an idea concerning the potency of our B. thuringiensis strains in the control of insect pests, a study to investigate their corresponding delta-endotoxins was conducted. For that, these proteins were extracted from the different isolates and their profiles and activities against Lepidoptera were investigated. 


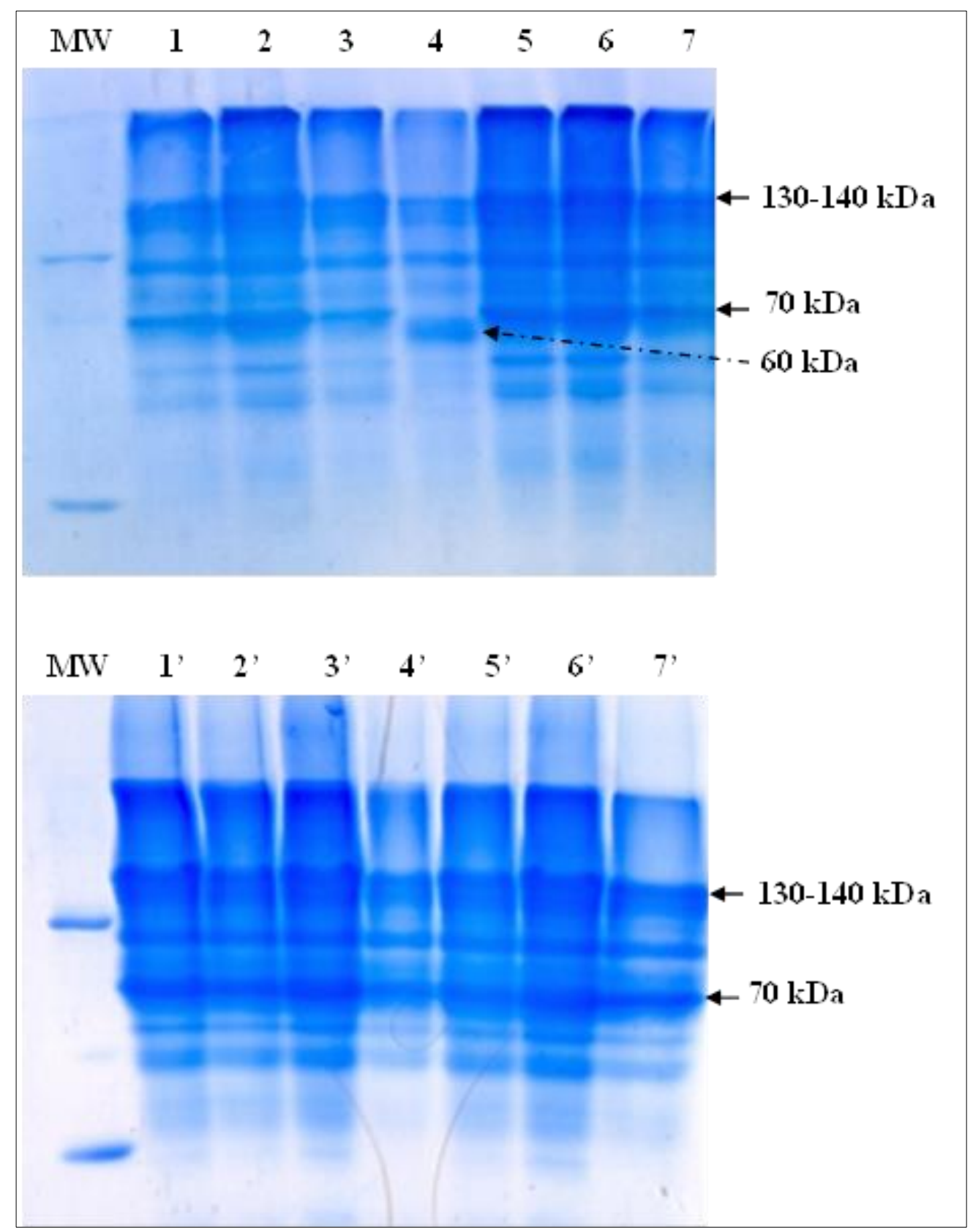

Figure 2 Analysis of $B$. thuringiensis inclusions content by SDS-PAGE

MW, Molecular weight marker; Lanes: 1-7, Crystal proteins extracted from isolates 1, 2, 4, 7, 8, 9 and 14, respectively; Lanes: 1' to 7', Crystal proteins extracted from isolates $15,16,17,18,22,23$ and 24 , respectively.

The study of delta-endotoxins content of the different $B$. thuringiensis isolates was achieved by extraction of the parasporal crystals according to the method described by El Khoury et al. [13]. Then, these crystals were solubilized and proteins were separated by SDS-PAGE in the presence of a molecular weight marker.

After electrophoresis in denaturing conditions, the obtained gels showed that parasporal crystals of all the studied isolates contained delta-endotoxins having almost similar molecular weights with the exception of isolate 7 (Figure 2, lane 4) that demonstrated a profile slightly different from the others. In fact, we noticed that all the parasporal crystals contained delta-endotoxin proteins of about 130-140 kDa (Figure 2). Moreover, all the isolates presented a second delta-endotoxin protein with a molecular weight rounding the $70 \mathrm{kDa}$, with the exception of isolate 7 in which the second delta-endotoxin has a size of about $60 \mathrm{kDa}$. In all the cases, different degradation bands were obtained (Figure 2). 


\subsection{Insecticidal activity of $B$. thuringiensis $\delta$-endotoxins against the lepidopteran pest $E$. kuehniella}

The presence of delta-endotoxins in B. thuringiensis new isolates encouraged us to test their activity. For that, these proteins were tested against the Lepidoptera E. kuehniella. Our choice was based mainly on the fact that this insect was known by its damages on different stored products such as flour, semolina, pasta and cereal grains.

By mixing semolina with delta-endotoxins, this media was used to feed neonate larvae of E. kuehniella and after 3 and 5 days, mortality was recorded and $\mathrm{LC}_{50}$ concentrations were determined using probit analysis.

Table 2 showed that, after 3 days of treatment, all crystal proteins were active against E. kuehniella with the exception of delta-endotoxins of the B. thuringiensis isolate 22 that was not active after this treatment duration. These results permitted the classification of $B$. thuringiensis isolates into three classes, class 1 with very high efficiency (Isolates 1,7 , 14 and 24), class 2 corresponding to isolates with less activity against E. kuehniella (Isolates 2, 4, 8, 9, 15, 16, 23 and 25) and class 3 with very low activity (Isolates 17 and 18), or without detected activity (Isolate 22).

Table 2 Toxicity of $B$. thuringiensis delta-endotoxins against E. kuehniella after 3 days of treatment

\begin{tabular}{|c|c|c|}
\hline Classification & Isolate number & $\mathrm{LC}_{50}\left(\mu \mathrm{g} / \mathrm{cm}^{2}\right)$ \\
\hline \multirow{4}{*}{ Class 1} & 1 & $109.98(+/-33.17)$ \\
\hline & 24 & $122.24(+/-31.75)$ \\
\hline & 14 & $136.50(+/-36.81)$ \\
\hline & 7 & $140.77(+/-33.54)$ \\
\hline \multirow{8}{*}{ Class 2} & 16 & $153.79(+/-36.35)$ \\
\hline & 4 & $163.98(+/-51.15)$ \\
\hline & 8 & $168.99(+/-59.43)$ \\
\hline & 25 & $169.95(+/-51.27)$ \\
\hline & 15 & $175.51(+/-51.27)$ \\
\hline & 2 & $175.57(+/-59.71)$ \\
\hline & 9 & $180.69(+/-51.12)$ \\
\hline & 23 & $185.52(+/-50.82)$ \\
\hline \multirow{3}{*}{ Class 3} & 17 & $224.02(+/-99.63)$ \\
\hline & 18 & $289.11(+/-174.72)$ \\
\hline & 22 & -------- \\
\hline
\end{tabular}

To confirm these results, the bioassay test was extended to 5 days and results were confirmed for the majority of the isolates. For the isolate 18, previously classified in class 3 , higher activity was detected allowing its classification in class 2. Moreover, the isolate 22 showing no activity against E. kuehniella after 3 days of treatment, was found to be active after 5 days (Table 3). Concerning isolates 18 and 22 showing much better activity against E. kuehniella larvae after 5 days treatment compared to that detected after 3 days, results can be explained by the lower activation rate of the protoxin in midgut larvae compared to that of delta-endotoxins of the other isolates. In fact, Bradley et al. [22] demonstrated that proteolysis of delta-endotoxins by protease midgut larvae is a key step in the mode of action of these toxins. Thus, after 5 days, activation of delta-endotoxins of B. thuringiensis isolates 18 and 22 occurred correctly and caused a decrease in the $\mathrm{LC}_{50}$ related with the increase of the activity against the tested Lepidoptera.

Delta-endotoxins of $B$. thuringiensis isolate 14 showed the most promising activity against the same Lepidoptera under same conditions with $\mathrm{LC}_{50}$ rounding the $59.18 \mu \mathrm{g} / \mathrm{cm}^{2}$ which makes this isolate promising in controlling insect pests. This activity was higher than that of HD1 and BLB459 delta-endotoxins described by Boukedi et al. [16]. 
Table 3 Toxicity of $B$. thuringiensis delta-endotoxins against E. kuehniella after 5 days of treatment

\begin{tabular}{|c|c|c|}
\hline Classification & Isolate number & $\mathrm{LC}_{50}\left(\mu \mathrm{g} / \mathrm{cm}^{2}\right)$ \\
\hline \multirow{4}{*}{ Class 1} & 14 & $59.18(+/-17.78)$ \\
\hline & 7 & $65.67(+/-23.45)$ \\
\hline & 24 & $66.73(+/-16.25)$ \\
\hline & 1 & $67.39(+/-26.68)$ \\
\hline \multirow{9}{*}{ Class 2} & 4 & $74.95(+/-27.24)$ \\
\hline & 16 & $79.63(+/-20.33)$ \\
\hline & 2 & $83.75(+/-28.19)$ \\
\hline & 25 & $86.62(+/-42.00)$ \\
\hline & 18 & $90.13(+/-49.83)$ \\
\hline & 15 & $92.29(+/-18.16)$ \\
\hline & 8 & $99.29(+/-27.76)$ \\
\hline & 9 & $109.84(+/-30.59)$ \\
\hline & 23 & $115.65(+/-29.93)$ \\
\hline \multirow{2}{*}{ Class 3} & 17 & $116.12(+/-35.09)$ \\
\hline & 22 & $168.99(+/-59.43)$ \\
\hline
\end{tabular}

\section{Conclusion}

The present study was undertaken to isolate and screen new B. thuringiensis strains for their aptitude to produce deltaendotoxins able to be used as biological agent to combat lepidopteran pests.

Fifteen B. thuringiensis strains were isolated from soil samples and classified according to different criteria such as parasporal crystal morphology, delta-endotoxins content and activity against the Lepidoptera E. kuehniella.

Promising results were obtained demonstrating that isolated $B$. thuringiensis strains are active against the stored products insect E. kuehniella and can be used in biological control programs against lepidopteran pests.

\section{Compliance with ethical standards}

\section{Disclosure of conflict of interest}

The authors: Kallaf, F.I., Dr. Boukedi H., Dr. Daâssi, D. and Pr. Abdelkefi-Mesrati L. have declared that there is no conflict of interest with the publication of this manuscript, institution as well as product that is mentioned in the manuscript.

\section{Statement of ethical approval}

The present research work does not contain any studies performed on animals/humans subjects by any of the authors.

\section{References}

[1] Dlott J, Perfecto I, Rosset P, Burkham L, Monterrey J, Vandermeer J. Management of insect pests and weeds. Agriculture and Human Values. 1993; 10: 9-15.

[2] Capinera JL. Relationships between insect pests and weeds: an evolutionary perspective. Weed Science. 2005; 53: 892-901. 
[3] Kumar S, Singh A. Biopesticides: Present status and the future prospects. Journal of Fertilizers and Pesticides. 2015; 6: 1-2.

[4] Rice PJ, Arthur EL, Barefoot AC. Advances in pesticide environmental fate and exposure assessments. Journal of Agricultural and Food Chemistry. 2007; 55(14): 5367-5376.

[5] Bjørling-Poulsen M, Andersen HR, Grandjean P. Potential developmental neurotoxicity of pesticides used in Europe. Environmental Health. 2008; 7(1): 1-22.

[6] Thakore Y. The biopesticide market for global agricultural use. Industrial Biotechnology. 2006; 2: 194-208.

[7] Schnepf E, Crickmore NV, Van Rie J, Lereclus D, Baum J, Feitelson J, Dean D. Bacillus thuringiensis and its pesticidal crystal proteins. Microbiology and Molecular Biology Reviews. 1998; 62(3): 775-806.

[8] Estruch JJ, Warren GW, Mullins MA, Nye GJ, Craig JA, Koziel MG. Vip3A, a novel Bacillus thuringiensis vegetative insecticidal protein with a wide spectrum of activities against lepidopteran insects. Proceedings of the National Academy of Sciences. 1996; 93: 5389-5394.

[9] Lee MK, Walters FS, Hart H, Palekar N, Chen JS. The mode of action of the Bacillus thuringiensis vegetative insecticidal protein Vip3A differs from that of Cry1Ab $\delta$-endotoxin. Applied and Environmental Microbiology. 2003; 69: 4648-4657.

[10] Phillips TW, Strand MR. Larval secretions and food odors affect orientation in female Plodia interpunctella. Entomologia Experimentalis et Applicata. 1994; 71(3): 185-192.

[11] Travers RS, Martin PA, Reichelderfer CF. Selective process for efficient isolation of soil Bacillus spp. Applied and Environmental Microbiology. 1987; 53(6): 1263-1266.

[12] Sharif FA, Alaeddinoĝlu NG. A rapid and simple method for staining of the crystal protein of Bacillus thuringiensis. Journal of Industrial Microbiology and Biotechnology. 1988; 3(4): 227-229.

[13] El Khoury M, Azzouz H, Chavanieu A, Abdelmalak N, Chopineau J, Awad MK. Isolation and characterization of a new Bacillus thuringiensis strain Lip harboring a new cry1Aa gene highly toxic to Ephestia kuehniella (Lepidoptera: Pyralidae) larvae. Archives of Microbiology. 2014; 196(6): 435-444.

[14] Laemmli UK. Cleavage of structural proteins during the assembly of the head bacteriophage T4. Nature. 1970; 227: 680-685.

[15] Abdelkefi-Mesrati L, Boukedi H, Chakroun M, Kamoun F, Azzouz H, Tounsi S, Rouis S, Jaoua S. Investigation of the steps involved in the difference of susceptibility of Ephestia kuehniella and Spodoptera littoralis to the Bacillus thuringiensis Vip3Aa16 toxin. Journal of Invertebrate Pathology. 2011; 107: 198-201.

[16] Boukedi H, Sellami S, Ktari S, Belguith-Ben Hassan N, Tounsi S, Abdelkefi-Mesrati L. Isolation and Characterization of a new Bacillus thuringiensis strain with a promising toxicity against Lepidopteran pests. Microbiological Research. 2016; 186: 9-15.

[17] Boukedi H, Ben Khedher S, Hadhri R, Jaoua S, Tounsi S, Abdelkefi-Mesrati L. Vegetative insecticidal protein of Bacillus thuringiensis BLB459 and its efficiency against Lepidoptera. Toxicon. 2017; 129: 89-94.

[18] Boukedi H, Hmani M, Ben Khedher S, Tounsi S, Abdelkefi-Mesrati L. Promising active bioinsecticides produced by Bacillus thuringiensis strain BLB427. World Journal of Advanced Research and Reviews. 2020; 8: 26-35.

[19] Venables WN, Smith DM. The R Development Core Team. An Introduction to R. Notes on R: A Programming Environment for Data Analysis and Graphics Version 1.9.1.2004.

[20] Martin PA, Travers RS. Worldwide abundance and distribution of Bacillus thuringiensis isolates. Applied and Environmental Microbiology. 1989; 55(10): 2437-2442.

[21] Nair K, Al-Thani R, Al-Thani D, Al-Yafei F, Ahmed T, Jaoua S. Diversity of Bacillus thuringiensis strains from Qatar as shown by crystal morphology, $\delta$-endotoxins and cry gene content. Frontiers in Microbiology. 2018; 9: 708.

[22] Bradley D, Harkey MA, Kim MK, Biever KD, Bauer LS. The insecticidal CryIB crystal protein of Bacillus thuringiensis ssp. thuringiensis has dual specificity to coleopteran and lepidopteran larvae. Journal of Invertebrate Pathology. 1995; 65(2): 162-173. 